REVISTA DE DERECHO UNED, NÚM. 13, 2013

\title{
LAS COMPETENCIAS LOCALES: UNA REFORMA PENDIENTE *
}

\author{
«LOCAL COMPETENCES: A PENDING REFORM»
}

\author{
SANTIAGO GARCÍA ARANDA
}

Doctor en Derecho

Resumen: Las competencias locales constituyen un elemento fundamental del principio general de la organización territorial del Estado que conocemos como "Autonomía local». Su regulación ha de efectuarse por el legislador básico estatal, y autonómico en desarrollo, en lo que a directrices para la asignación de competencias se refiere y, a su vez, por el legislador autonómico o estatal, según la materia. Todo ello hace de esta una tarea de gran complejidad que, aún habiéndose exigido al legislador por el Tribunal Constitucional hace más de 30 años, a día de hoy sigue pendiente. Ante la posibilidad inminente de una nueva regulación se estudia el estado de la cuestión, incluyéndose aspectos imprescindibles a considerar por una nueva legislación.

Palabras clave: Competencias locales, autonomía local, reforma régimen local, modelo competencial local.

Abstract: Local competences are a key element of the general principle of the territorial organization of the state is known as «local autonomy». Its regulation is to be effected by the basic state legislator, and regional development, as far as guidelines for the

En el transcurso de la edición de la presente publicación se produjo la entrada en vigor de la Ley 27/2013, de 27 de diciembre, de racionalización y sostenibilidad de la Administración Local, por lo que ha de entenderse a ella referido todo cuanto se atribuye en el presente artículo al Proyecto de Ley de idéntica denominación, toda vez que las previsiones del Proyecto no han experimentado modificaciones que afecten al contenido de este trabajo. 
allocation of competences concerns, in turn, by the regional or state legislator, by subject-matter. This is a very complex task which, although it was required of the legislator by the Constitutional Court over 30 years ago, today is still pending. Faced with the imminent possibility of a new regulation examines the state of affairs, including essential aspects to be considered by new legislation.

Keywords: local competences, local autonomy, local government reform, the local competence model.

Recepción original: 15/10/2013

Aceptación original: 30/10/2013

Sumario: 1) Introducción. 2) La reserva de Ley. 3) Las competencias locales y el legislador. 4) Las competencias locales en la Carta Europea de la Autonomía Local. 5) Las competencias locales: Clasificación. 6) Las competencias locales en el Proyecto de Ley de racionalización y sostenibilidad de la Administración Local. 7) A modo de conclusión.

\section{1) INTRODUCCIÓN}

En esta ocasión, con la denominación de «Ley de racionalización y sostenibilidad de la Administración Local» el actual Ejecutivo pretende acometer una reforma del régimen local donde, entre otros, se persigue el objetivo de clarificar las competencias locales para así evitar lo que califica como situación de solapamientos competenciales entre Administraciones. Son numerosos los autores de la doctrina administrativista y también constitucionalista que han reclamado una revisión del actual modelo competencial, elemento fundamental del principio general de la organización territorial del Estado que, singularmente tras la Constitución de 1978, conocemos por «Autonomía local». Resulta de sumo interés, por tanto, cualquier aspecto regulatorio que se detenga en lo relativo a las competencias ${ }^{2}$ de los

2 La Autonomía local puede definirse como el derecho de los entes locales a participar en la gestión y administración de aquellos asuntos que sean de su interés. Y es ahí, donde el estudio de la consideración de las competencias locales como mecanismo a través del cual se materializa el derecho a participar en los asuntos de interés local, adquiere toda su importancia para una más completa definición y conocimiento de la Autonomía local. La misma Ley de Bases del Régimen Local en su artículo 2.1 así lo establece sin dejar lugar a dudas cuando dice «...la legislación del Estado y la de las Comunidades Autónomas, reguladora de los distintos sectores de acción publica, según la distribución constitucional de competencias, deberá asegurar a los Municipios, las Provincias y las Islas su derecho a intervenir en cuantos asuntos 
entes locales y, por ende, en la definición del denominado contenido objetivo $^{3}$ de la Autonomía local, pues éste viene a constituir una fundamental contribución a la conceptuación del principio general señalado. Es por todos conocido cómo entre los elementos defendidos y protegidos por la técnica de la garantía institucional ${ }^{4}$ se encuentra el relativo al derecho a la intervención de las entidades locales en la gestión de sus intereses ${ }^{5}$, lo que solamente puede llevarse a cabo ejerciendo las competencias que les correspondan o, mejor, que se les asignen ${ }^{6}$. Y, por ello, siguiendo al Profesor Joaquín GARCÍA MORILLO cuando señala que la Constitución quiere, también, que los

afecten directamente al círculo de sus intereses, atribuyéndoles las competencias que proceda en atención a las características de la actividad pública de que se trate y a la capacidad de gestión de la entidad local, de conformidad con los principios de descentralización y de máxima proximidad de la gestión administrativa a los ciudadanos».

3 FANLO LORAS hablará del plano objetivo de la garantía institucional de la autonomía local, al que se unirán los planos subjetivo e institucional (refiriéndose, junto al ámbito competencial, a la garantía de la existencia, por un lado, y de la responsabilidad, por otro, de los entes locales). FANLO LORAS, A., Fundamentos constitucionales de la autonomía local. El control sobre las Corporaciones Locales. El funcionamiento del modelo constitucional de autonomía local, Centro de Estudios Constitucionales, Madrid, 1990.

4 Técnica de protección que tiene su origen en el Derecho alemán y fue introducida por la doctrina administrativista con una rápida aceptación y aplicación por parte del Tribunal Constitucional que, en su Sentencia 32/81, de 28 de julio, hizo uso de ella en la salvaguarda que este instrumento ofrece para la Autonomía local, calificando las instituciones locales de «elementos arquitecturales indispensables del orden constitucional» pero, como precisará más tarde en la Sentencia 109/98, de 21 de mayo, «la garantía institucional de la autonomía local no asegura un contenido concreto ni un determinado ámbito competencial sino la preservación de una institución en términos recognoscibles para la imagen que de la misma tiene la conciencia social en cada tiempo y lugar...».

5 A este respecto, es digna de mención la consideración de GARCÍA ROCA en "El concepto actual de autonomía local según el bloque de constitucionalidad» en Estudios de Derecho Constitucional. Homenaje al Profesor... op. cit. pp. 657-658, donde afirma como «uno de los grandes problemas del Derecho Español y, en particular, de la Teoría del Estado española ha sido - a juicio de muchos-un exceso de traducciones de textos alemanes y franceses en detrimento de una verdadera reflexión propia» y señala cómo en Alemania la autonomía local es considerada como un derecho asimilable a los derechos fundamentales, mientras que en España no es considerado como tal. Y pone de manifiesto las complicaciones que resultan cuando por seguir otras teorizaciones ajenas se incurre en "papanatismos»-llega a decir- como en el caso de la autonomía universitaria y su consideración como derecho fundamental.

6 Así, numerosas Sentencias del Tribunal Constitucional (STC 32/1981, 27/1987, 170/1989) han reiterado que "Esa garantía institucional supone el derecho de la comunidad local a participar, a través de de órganos propios, en el gobierno y administración de cuantos asuntos le atañen, graduándose la intensidad de esta participación en función de la relación existente entre los intereses locales y supralocales dentro de tales asuntos o materias. Para el ejercicio de esa participación en el gobierno y administración de cuanto le atañe, los órganos representativos de la comunidad local han de estar dotados de las potestades sin las que ninguna actuación autonómica es posible». 
entes locales existan, pero que existan para el cumplimiento de una serie de funciones (que, como veremos, deberán establecerse por el legislador estatal o autonómico, según corresponda), es la pretensión de este trabajo el estudio de esas funciones que vienen a constituir el contenido objetivo de la Autonomía local y, por tanto, la definición de su ámbito material, esto es, las competencias locales. Son de indiscutible importancia los trabajos ya publicados acerca de nuestro modelo competencial local ${ }^{7}$ y este breve estudio pretende apoyarse en lo más relevante de sus aportaciones con objeto de ofrecer al legislador un material con que contribuir a la necesaria y tremendamente compleja tarea de clarificación de lo que viene a constituir el plano objetivo de la garantía institucional de la autonomía local ${ }^{8}$.

\section{2) LA RESERVA DE LEY}

El artículo 137 de la Constitución Española proclama que los entes locales territoriales gozan de autonomía para la gestión de sus respectivos intereses, pero no se encontrará en nuestro Texto Fundamental una relación de materias sobre las que los mencionados entes hayan de ejercer las competencias oportunas, propias de la autonomía correspondiente. Así pues, la definición de cuáles serán esos intereses $^{9}$ (locales en nuestro caso) sobre las materias cuya regulación,

7 Son muy numerosos los autores que han hecho aportaciones imprescindibles en el ámbito de estudio de las competencias locales, entre otros, ORTEGA ÁLVAREZ, FONT I LLOVET, SÁNCHEZ MORÓN, SOSA WAGNER, FANLO LORAS, PAREJO ALFONSO, GARCÍA ROCA, GARCÍA FERNÁNDEZ, GARCÍA MORILLO, VELASCO CABALLERO, PARADA VÁZQUEZ FERNÁNDEZ RODRÍGUEZ, CARRO FERNÁNDEZ-VALMAYOR, ROÁS MARTÍN, MERINO ESTRADA, CAAMAÑO RODRÍGUEZ, MARTÍN MATEO, REQUEJO RODRÍGUEZ, MEDINA GUERRERO, AJA FERNÁNDEZ, BANDRÉS SÁNCHEZ-CRUZAT, LÓPEZ GARCÍA, etc.

8 Todo ello, a la vista de la nula disposición del Tribunal Constitucional al abandono de esta técnica exclusivamente defensiva que jugó su papel protector pero que, en la actualidad, resulta francamente limitada para la definición del contenido de una institución que ha de cumplir las funciones que la Constitución le encomienda.

9 La recurrencia a la existencia o no del interés local como elemento diferenciador para la atribución de competencias es una clara herencia de la Revolución francesa y su concepción del «pouvoir municipal» que, si bien no negamos su utilidad teórica en su momento histórico, hoy puede venir a constituirse en un obstáculo para la articulación de la intervención de los entes locales en una situación como la actual, en la que es de suma dificultad encontrar intereses que estricta y exclusivamente afecten a una única administración territorial, tratándose en la práctica totalidad de los casos de intereses de orden casi general que requieren de la participación de más de una administración. Como veremos, la consecuencia fundamental de este modelo asentado en el «interés local» será la extrema dificultad para el establecimiento de relaciones claras y específicas de competencias normativas locales, o ejecutivas en su caso. 
sectorialmente, corresponde a Estado y Comunidades Autónomas, y qué atribución competencial se confiere a los entes locales, es una tarea que deberá llevarse a cabo mediante Ley formal. En términos del Tribunal Constitucional (STC 109/1998, de 21 de Mayo), y acerca del ámbito competencial de las Diputaciones Catalanas, "no precisa la Constitución cuáles sean estos intereses ni cual el haz mínimo de competencias que para atender a su gestión debe el legislador atribuir a la provincia, aunque sí cabe derivar de la Constitución razones que apuntan a la posibilidad de que estos intereses provinciales y las competencias que su gestión autónoma comporta han de ser inflexionados para acomodar esta pieza de nuestra estructura jurídico-política a otras entidades autonómicas de nueva creación». Y en la misma Sentencia, retomando lo ya señalado en la STC 84/1982, insiste en que "Los entes locales (municipios y provincias) tienen autonomía constitucionalmente garantizada para la gestión de sus respectivos intereses (artículo 137 de la CE); la determinación de cuáles sean estos intereses es obra de la ley, que les atribuye, en consecuencia, competencias concretas, pero que, en todo caso, debe respetar la autonomía y, como substrato inexcusable de ésta, reconocerles personalidad propia».

Por otro lado, es en lo relativo al aspecto competencial donde el estudio previo de la naturaleza, grado y alcance de la Autonomía de los entes locales, su garantía institucional y, singularmente, la expresión «régimen bifronte» adquieren la plenitud de su sentido. Ciertamente, la presencia del elemento democrático vendrá a garantizar el derecho a intervenir de los entes locales en aquellos asuntos que les afecten pero las dificultades aparecerán al llegar el momento de establecer el listado de materias así como la naturaleza, grado y alcance de la intervención ${ }^{10}$. Por otra parte, a la vista de la jurisprudencia constitucional sobre la materia, ha quedado claro que la técnica de la Garantía Institucional no aporta una relación de competencias a ejercer sobre materias en las que los entes locales tienen derecho a la mencionada intervención. Y el hecho cierto es que la distribución de competencias sobre relaciones de materias, solamente, se establece por nuestra Constitución para el Estado y para las Comunidades Autónomas, quedando municipios y provincias (también islas, como resulta obvio señalar) a la espera del resultado de la actividad legis-

10 Como se ha indicado, el esquema constitucional de distribución o reparto de competencias sobre las distintas materias relacionadas, básicamente, en los artículos 148 y 149 hace que sea la Ley formal el eje de su conformación última. Y es ahí donde adquiere toda su importancia la ausencia de potestad legislativa en nuestros entes locales que, de modo insistente, parte de la doctrina señala como elemento determinante al caracterizar la naturaleza de la Autonomía local como administrativa frente a las tesis que la entienden como política. 
lativa de aquellos ${ }^{11}$, en lo relativo a las materias respecto de las que ejercer las competencias que proceda. Así pues, además de para la conceptuación de la Autonomía de los entes locales, las nociones de garantía institucional y régimen bifronte constituyen elementos de estudio que nos proporcionan las claves fundamentales para la comprensión del esquema competencial en el ámbito local.

Tal y como se ha señalado anteriormente, el sistema de atribución de competencias que establece la Ley Reguladora de las Bases del Régimen Local se caracteriza, en primer lugar, por una reserva de materias ${ }^{12}$ en las que el legislador sectorial, bien sea el Estado, bien la Comunidad Autónoma, se encuentra necesariamente obligado a respetar un margen de ejercicio competencial a los entes locales. Y, una vez se ha sentado la necesaria intervención local, cabrá la acción de la legislación sectorial identificando los intereses locales en juego ${ }^{13}$ y procediendo, consiguientemente, a la asignación de las competencias que, en función de éstos, corresponda ${ }^{14}$. O, en

11 Desde el principio será imprescindible insistir en que, como de modo extremadamente claro señala la profesora Paloma REQUEJO, «en la construcción de los aspectos institucionales, funcionales y competenciales de la autonomía local a partir del núcleo esencial constitucionalmente establecido participa, además del legislador básico estatal, el legislador sectorial estatal y el legislador autonómico tanto de desarrollo como sectorial.» REQUEJO RODRÍGUEZ, P. en "El nuevo diseño de las competencias locales», en Cuadernos de Derecho Local n. ${ }^{\circ}$ 13, Febrero de 2007. Fundación Democracia y Gobierno Local, p. 26.

12 Sin perjuicio de lo previsto en el 26.1 de la Ley Reguladora de las Bases del Régimen Local, estaríamos hablando de, por ejemplo, las recogidas, para los municipios, en el artículo 25.2 que, con gran rotundidad, dice la Ley «ejercerá en todo caso». Y, por asignación directa de la LRBRL en su artículo 31.2, de las atribuidas para las provincias.

13 Es de suma importancia insistir en la necesaria y obligatoria identificación del interés local pues, al ser fruto de una decisión política, podría aparecer la tentación de una arbitraria negación de la consideración de un asunto como de interés local y ahí debe jugar un papel fundamental el artículo 2 de la LRBRL cuando menciona las características de la actividad pública de que se trate, la capacidad de gestión de la entidad local y, sobre todo, cuando se refiere al principio constitucional de descentralización, del artículo 103.1 de la norma fundamental, o de la máxima proximidad de la gestión administrativa a los ciudadanos, que también puede ponerse en relación con el derecho de los ciudadanos a participar en la vida política, económica, cultural y social, del artículo 9.2 de la Constitución.

14 La asignación de competencias, obviamente por parte del legislador competente por razón de la materia, deberá llevarse a cabo, no de cualquier manera, sino respetando la íntima vinculación de los principios Democrático y de Autonomía pues, al tratarse de un ámbito local de decisión política, la entidad debe disponer sobre el asunto o materia en cuestión de un contenido competencial suficiente que permita, por tanto, distintas ofertas políticas. Por otra parte, la Carta Europea de Autonomía Local, tal y como se ha señalado, introduce en su artículo 3.1 la expresión «una parte importante de los asuntos públicos» que refuerza de modo significativo la necesaria relevancia del paquete competencial a asignar. A este respecto, Francisco 
términos del artículo 2.1 de la LRBRL, las competencias que proceda en atención a las características de la actividad pública de que se trate y a la capacidad de gestión de la entidad local, de conformidad con los principios de descentralización y de máxima proximidad de la gestión administrativa a los ciudadanos. Y esas competencias podrán distinguirse por ser competencias normativas, que en el caso local se manifiestan en la aprobación de las correspondientes disposiciones normativas de carácter reglamentario (Reglamentos, Ordenanzas y Bandos), o competencias ejecutivas, en las que se debe atribuir, no obstante, una cierta capacidad de decisión sobre los asuntos en los que prevalezca un interés local.

\section{3) LAS COMPETENCIAS LOCALES Y EL LEGISLADOR}

Así pues, sentado que Autonomía y competencias son nociones perfectamente unidas ${ }^{15}$, y que las materias sobre las que ejercer la intervención local oportuna -así como la intervención misma- han de ser reguladas por ley formal, procede, a continuación, el estudio del que podríamos denominar mecanismo de atribución o asignación de competencias o, en otras palabras, ¿quién será el legislador competente? ¿sobre qué materias habrá de legislarse la intervención local? y ¿qué competencias cabe atribuir?

Tal y como establece la Sentencia del Tribunal Constitucional 214/1989, de 21 de diciembre, en su fundamento jurídico segundo, "...corresponde al legislador estatal la fijación de los principios básicos en orden a las competencias que deba reconocerse a las entidades locales, estableciendo y garantizando, al fin, su derecho a intervenir en cuantos asuntos afecten directamente al círculo de sus intereses y fijando al respecto unas directrices para llevar a cabo la asignación de tales competencias, directrices que se concretan en atender, en cada

SOSA señala de modo taxativo que "Si las leyes no dejan el suficiente espacio a las Corporaciones locales para que éstas puedan hacer opciones politicas (y no simplemente administrar), es mejor modificar el modelo mismo, suprimir el carácter democrático de las Corporaciones y confiar los servicios a organizaciones especializadas». SOSA WAGNER, F., Aproximación básica a las competencias locales (15-30), en PARADA VÁZQUEZ, R. Y FERNÁNDEZ RODRÍGUEZ, C. (dirs.) Las competencias locales, Fundación Caja Rural de Toledo-Marcial Pons, Madrid-Barcelona-Buenos Aires, 2007.

15 Expresión tomada de SOSA WAGNER en «Aproximación a las competencias locales» en, PARADA VÁZQUEZ, R. y FERNÁNDEZ RODRÍGUEZ, C. (dirs.), Las competencias..., op. cit., p. 19. O «nociones íntimamente ligadas» que dirá REQUEJO RODRÍGUEZ, P., "El nuevo diseño de las competencias locales», en Cuadernos de Derecho Local n. ${ }^{\circ}$ 13, Fundación Democracia y Gobierno Local, Febrero de 2007, p. 28. 
caso, a las características de la actividad pública y a la capacidad de gestión de la entidad local, de acuerdo con los principios de descentralización y máxima proximidad de la gestión administrativa a los ciudadanos.» De modo que nuestra jurisprudencia constitucional deja claro que el legislador básico sobre régimen local ha de jugar el papel correspondiente en materia competencial ${ }^{16}$, por su parte el legislador autonómico podrá completar al amparo del $148.12^{\mathrm{a}} \mathrm{CE}$ lo establecido por el legislador básico del régimen local, y todo ello sin perjuicio de la función que habrán de desempeñar los legisladores sectoriales competentes sobre las materias en las que los entes locales tengan derecho a intervenir ${ }^{17}$. El artículo 2.1 de la Ley de Bases de Régimen Local señala que "Para la efectividad de la autonomía garantizada constitucionalmente a las entidades locales, la legislación del Estado y la de las Comunidades Autónomas, reguladora de los distintos sectores de acción publica, según la distribución constitucional de competencias, deberá asegurar a los Municipios, las Provincias y las Islas su derecho a intervenir en cuantos asuntos afecten directamente al círculo de sus intereses, atribuyéndoles las competencias que proceda en atención a las características de la actividad pública de que se trate y a la capacidad de gestión de la entidad local, de conformidad con los principios de descentralización y de máxima proximidad de la gestión administrativa a los ciudadanos.» Como observamos, el mecanismo o modelo de asignación competencial establecido por este precepto impone al legislador sectorial, bien sea autonómico o estatal, el deber de asegurar a los entes locales territoriales de existencia obligatoria (municipios, provincias e islas) el derecho a intervenir en

16 Ya en su Sentencia 32/2981, de 28 de julio señaló el Tribunal Constitucional que corresponde al Estado «la fijación de principios o criterios básicos en materia de organización y competencia». Por su parte, muy acertadamente aclara Paloma REQUEJO que la función del legislador básico consistiría no tanto en llevar a cabo la concreción de las competencias a asignar y la determinación de su alcance, puesto que ello excedería el concepto de bases e invadiría el espacio del legislador sectorial, sino en establecer los criterios a seguir cuando esa asignación tenga lugar y en establecer las materias en las que se considera indispensable que los entes locales tengan alguna competencia propia para satisfacer sus intereses. REQUEJO RODRÍGUEZ, P., «El nuevo diseño de las competencias locales», en Cuadernos de Derecho Local..., op. cit., p. 29.

17 Como se ha señalado anteriormente, la Constitución no contiene una relación de materias sobre las que se atribuyan de modo expreso competencias a los entes locales por lo que nos estaríamos refiriendo aquí a los legisladores estatal y autonómico competentes por razón de la materia en virtud, ahora sí, de la distribución efectuada por el propio texto constitucional. Por otra parte, en el caso de las materias compartidas habrá de ser el legislador básico estatal quien establezca qué competencias corresponderán a las entidades locales, siempre con la limitación de garantizar la autonomía local y, todo ello, sin excederse pues no deberá invadir las competencias comunitarias tal y como aclaró la STC 214/1989 en el tercero de sus fundamentos jurídicos. 
aquellos asuntos que afecten directamente al círculo de sus intereses, atribuyéndoles las competencias que corresponda.

En el modelo que se establece a través de la vigente Ley de Bases del Régimen Local de 1985 se recogen, asimismo, las materias sobre las que deberá, el legislador sectorial, atribuir la competencia que proceda a los entes locales correspondientes. Lo hace en su artículo 25.2: "El Municipio ejercerá, en todo caso, competencias, en los términos de la legislación del Estado y de las Comunidades Autónomas, en las siguientes materias: Seguridad en lugares públicos, Ordenación del tráfico de vehículos y personas en las vías urbana, Protección civil, prevención y extinción de incendios, Ordenación, gestión, ejecución y disciplina urbanística; promoción y gestión de viviendas; parques y jardines, pavimentación de vías públicas urbanas y conservación de caminos y vías rurales, Patrimonio histórico-artístico, Protección del medio ambiente, Abastos, mataderos, ferias, mercados y defensa de usuarios y consumidores, Protección de la salubridad pública, Participación en la gestión de la atención primaria de la salud, Cementerios y servicios funerarios, Prestación de los servicios sociales y de promoción y reinserción social, Suministro de agua y alumbrado público; servicios de limpieza viaria, de recogida y tratamiento de residuos, alcantarillado y tratamiento de aguas residuales, Transporte público de viajeros, Actividades o instalaciones culturales y deportivas; ocupación del tiempo libre; turismo, Participar en la programación de la enseñanza y cooperar con la Administración educativa en la creación, construcción y sostenimiento de los centros docentes públicos, intervenir en sus órganos de gestión y participar en la vigilancia del cumplimiento de la escolaridad obligatoria.». Donde, como se observará, se relacionan las materias que, en gran medida, vienen a coincidir con aquellas en las que las Comunidades Autónomas podrán asumir competencias, tal y como proclama el artículo 148.1 CE, y lo completa con el artículo 26.1 «Los Municipios por sí o asociados deberán prestar, en todo caso, los servicios siguientes: En todos los Municipios: alumbrado público, cementerio, recogida de residuos, limpieza viaria, abastecimiento domiciliario de agua potable, alcantarillado, acceso a los núcleos de población, pavimentación de las vías públicas y control de alimentos y bebidas. En los Municipios con población superior a 5000 habitantesequivalentes, además: parque público, biblioteca pública, mercado y tratamiento de residuos. En los municipios con población superior a 20000 habitantes-equivalentes, además: protección civil, prestación de servicios sociales, prevención y extinción de incendios e instalaciones deportivas de uso público. En los Municipios con población superior a 50.000 habitantes-equivalentes, además: transporte colectivo urbano 
de viajeros y protección del medio ambiente.». El sistema viene a completarse, para el municipio, con lo que Paloma REQUEJO denomina la declaración general de capacidad ${ }^{18}$ del artículo 25.1 que, según destacados sectores de la doctrina, establecería una cláusula general de competencia municipal ${ }^{19}$ : "El municipio, para la gestión de sus intereses y en el ámbito de sus competencias, puede promover toda clase de actividades y prestar cuantos servicios públicos contribuyan a satisfacer las necesidades y aspiraciones de la comunidad vecinal». De modo que los municipios podrán desarrollar toda clase de actividades que consideren de interés para su comunidad, sean las que las leyes les permitan o, en el supuesto de ausencia de regulación legal, sean aquellas que les afecten en el ámbito de sus intereses. Y, dicha cláusula general ${ }^{20}$, vendría a ser una competencia de carácter

18 REQUEJO RODRÍGUEZ, P., "El nuevo diseño de las competencias locales», en Cuadernos de Derecho Local..., op. cit., p. 30.

19 Las diferencias doctrinales radicarían en la lectura del artículo 25 de la LRBRL por contener su redacción la expresión en el ámbito de sus competencias. En el derecho alemán existe la capacidad de intervención del municipio en cualquier materia propia de la competencia de una Administración pública, la llamada cláusula de la competencia general de los municipios que hay quien pretende limitar en el derecho español apoyándose en la expresión ya mencionada del ámbito de sus competencias. SOSA WAGNER argumenta que si el artículo 31 de la Ley de Bases atribuye a la provincia la general expresión fomento y administración de sus intereses peculiares, no cabe aceptar que el legislador haya querido configurar la provincia (con un mecanismo de elección indirecta) como un ente de mayor autonomía y fortaleza que el municipio (con una corporación elegida de modo directo). E interpreta el artículo 25 afirmando que lo que el legislador afirma cuando señala en el ámbito de sus competencias es que el municipio actúa en el marco y de acuerdo con las leyes, entre las que se incluye la Ley de Bases, que le atribuye competencia general más allá de las específicamente atribuidas por las leyes siempre que se refieran a asuntos que afecten directamente al círculo de sus intereses (los que se hagan presentes y se puedan resolver dentro del término municipal). Refuerza, además, Francisco SOSA, este argumento con el principio de subsidiariedad (atribución de competencias y responsabilidades públicas a las autoridades más próximas a los ciudadanos que se encuentren en condiciones de ejercerlas) tomando, además, la expresión "primacía de la voluntad municipal» de la Sentencia de 3 de abril de 1998, del Tribunal Supremo. SOSA WAGNER, F., Aproximación básica a las competencias locales (15-30), en PARADA VÁZQUEZ, R. Y FERNÁNDEZ RODRÍGUEZ, C. (dirs.) Las competencias locales, Barcelona, 2007. Encontramos en esta línea, apoyándose en las tesis de LEGUINA VILLA, a RUIZ CUADRADO, B. en La Autonomía local y su defensa. Anales de Derecho, n. ${ }^{\circ} 16,1998$.

20 También ha sido denominada «Cláusula de interés general» por LÓPEZ GARCÍA al tiempo que menciona el desarrollo o concreción de la misma, en determinadas materias (educación y cultura, promoción de la mujer, la vivienda, la sanidad y el medio ambiente), por el artículo 28 de la LBRL, facultando a los municipios para realizar las llamadas «actividades complementarias». LÓPEZ GARCÍA, C., Nuevo sistema de atribución y defensa competencial de las entidades locales, en Cuadernos de Derecho Local n. ${ }^{\circ}$ 15, Fundación Democracia y Gobierno Local, Octubre de 2007. P. 111 . 
residual para los municipios que les puede permitir desarrollar toda clase de actividades de interés para la comunidad, siempre y cuando no hayan sido legalmente reservadas a otra Administración ${ }^{21}$. Cabría, por tanto, contemplar la posibilidad de una presunción de competencia a favor de los municipios tal y como señala SOSA WAGNER. Por su parte, los profesores NÚÑEZ RIVERO, GOIG MARTÍNEZ y NÚÑEZ MARTÍNEZ, abundan en esa línea llamando la atención sobre lo previsto en el artículo 86 de la misma Ley de Bases, donde se atribuye a las Entidades locales facultades en materia de iniciativa pública para el ejercicio de actividades económicas conforme al 128.2 CE, lo que vendría a sumarse a lo establecido en materia de competencias por los artículos señalados anteriormente ${ }^{22}$.

Por su parte, la provincia tiene reguladas sus competencias en el artículo 36 «Son competencias propias de la Diputación las que les atribuyan, en este concepto, las leyes del Estado y de las comunidades autónomas en los diferentes sectores de la acción pública, y en todo caso: La coordinación de los servicios municipales entre sí para la garantía de la prestación integral y adecuada a que se refiere el apartado a del número 2 del artículo 31. La asistencia y la cooperación jurídica, económica y técnica a los Municipios, especialmente los de menor capacidad económica y de gestión. La prestación de servicios públicos de carácter supramunicipal y, en su caso, supracomarcal. La cooperación en el fomento del desarrollo económico y social y en la planificación en el territorio provincial, de acuerdo con las competencias de las demás Administraciones Públicas en este ámbito. En general, el fomento y la administración de los intereses peculiares de la provincia» ${ }^{23}$.

\section{4) LAS COMPETENCIAS LOCALES EN LA CARTA EUROPEA DE LA AUTONOMÍA LOCAL}

Las competencias locales han sido también objeto de atención por la Carta Europea de la Autonomía Local. Esta es un Tratado interna-

21 CARRO FERNÁNDEZ-VALMAYOR, J. L., "El debate sobre la autonomía municipal», Revista de Administración Pública, n. ${ }^{\circ}$ 147, 1998. P. 93.

22 GOIG MARTÍNEZ, J.M., NÚÑEZ RIVERO, C., NÚÑ̃Z MARTÍNEZ, M., La Constitución Española en la Jurisprudencia del Tribunal Constitucional. Vol. I, Ed. Universitas, Madrid, 2010, p. 288.

23 Sobre las competencias provinciales veasé el interesantísimo estudio de CACHARRO GOSENDE, F., Las competencias de las diputaciones provinciales de régimen común en Cuadernos de Derecho Local n. ${ }^{\circ} 10$, Fundación Democracia y Gobierno Local, febrero de 2006. 
cional $^{24}$, finalmente redactado y firmado por los Estados miembros del Consejo de Europa en octubre de 1985, ratificado por España, previa autorización de las Cortes Generales tal y como establece el artículo $94.1^{25}$ de la Constitución, el 20 de enero de 1988, con entrada en vigor de forma general el 1 de septiembre del mismo año y, para nuestro caso concreto el 1 de marzo de 1989. No obstante, hay que señalar que su aplicación en nuestro país se produjo con la debida reserva sobre el artículo 3.2, al contener éste la necesidad de elección mediante sufragio libre, secreto, directo y universal -dice la Carta- que nuestra normativa no recoge en idénticos términos (por indirecto) en el caso de los miembros de las corporaciones provinciales y otras entidades locales distintas de las territoriales de carácter necesario $^{26}$.

La Carta Europea de la Autonomía Local dedica un artículo a las competencias locales, el cuarto, donde establece, con la flexibilidad que caracteriza a todo el Tratado, el «alcance de la autonomía local» afirmando que las competencias básicas de las Entidades locales se fijarán "por la Constitución o la Ley», permitiéndose la atribución de competencias a las mismas, de nuevo, "de conformidad con la Ley». El apartado segundo de este artículo, incidiendo en la necesidad de que a las Entidades locales se les atribuyan competencias propias y básicas, recoge una suerte de competencia residual ${ }^{27}$. Y el apartado tercero de este artículo reconoce el principio de subsidiariedad ${ }^{28}$ a

24 Este Tratado tuvo como antecedentes la «Carta Europea de las Libertades Municipales» de 1953, la «Resolución 64» del Comité de Poderes Locales y Regionales de Europa, de 1968, y la «Recomendación 615» de la Asamblea Parlamentaria del Consejo de Europa, de 1970.

${ }_{25}$ Por parte de la doctrina se ha encajado en diversos apartados del propio artículo 94.1, pues no se estableció expresamente al amparo de cual de ellos se prestó la previa autorización para la Carta. Así, ha podido entenderse como un Tratado de carácter político del apartado a), como un Tratado que afecta a los derechos y deberes fundamentales del apartado c) -ya hemos hecho, en el apartado anterior, mención de la corriente que pretende considerar la Autonomía local desde la perspectiva del derecho fundamental a la participación política del artículo 23 de la Constitución-, o como un Tratado que supone las modificaciones legislativas del apartado e).

26 Otros Estados, y por razones varias, también establecieron reservas a la Carta, son los casos, por ejemplo, de Alemania, Austria, Chipre, Dinamarca, Liechtenstein, etc.

27 "Las Entidades locales tienen, dentro del ámbito de la Ley, libertad plena para ejercer su iniciativa en toda materia que no esté excluida de su competencia o atribuida a otra autoridad».

28 La subsidiariedad entendida a la luz de la Carta Europea de Autonomía Local no se justificaría tanto en la necesidad de conseguir el interés general desde lo local, como muy bien afirma SÁNCHEZ SÁEZ, sino más bien en el «prejuicio» de que las Administraciones locales pueden ser más eficaces que las superiores en una gran cantidad de materias. SÁNCHEZ SÁEZ, A. en Autonomía local y descentralización. Tirant lo Blanch, Valencia, 2008, p. 35. 
favor de los Entes locales en razón a su mayor cercanía aunque, en palabras de REQUEJO PAGÉS, con una vocación más orientativa que imperativa tal y como ponen de manifiesto expresiones como "de modo general», "preferentemente» o "debe tener en cuenta» ${ }^{29}$. El apartado cuarto, por su parte, establece la necesidad de que las competencias de las Entidades locales «deben ser normalmente plenas y completas" sin deberse cuestionar por otros poderes, regionales o centrales, más que dentro del ámbito de la Ley. Se establece, a continuación, que en el caso de «delegación de poderes las Entidades locales deben disfrutar en lo posible de la libertad de adaptar su ejercicio a las condiciones locales». Y termina este artículo cuarto con la necesidad de que las Entidades locales sean consultadas, de nuevo con expresiones poco firmes y nada tajantes, "en la medida de lo posible», en los procesos de planificación y decisión que les afecten directamente.

Pero lo cierto es que es este un Tratado Internacional que, probablemente por su propia condición y con objeto de facilitar un máximo de adhesiones en el Consejo de Europa, deja demasiado margen a las normas internas de carácter legal para «enmarcar» la Autonomía local. Ya se han mencionado las numerosas expresiones del tipo de "en la medida de lo posible», "de conformidad con la Ley», "en el marco de la Ley», "permitido por la Ley», "dentro del ámbito de la Ley», "dentro de los límites de la Ley», etc. que, en el caso español, caracterizan aún más intensamente una vinculación positiva de la Autonomía local a las leyes. Y esa vinculación positiva no está tan clara en lo que parece sean los deseos de la Carta Europea al proponer la lectura de la Autonomía local como derecho a decidir y capacidad efectiva de las Entidades locales "en el marco de la ley», lo que permitiría una vinculación negativa pudiendo actuar en aquellos ámbitos que la Ley no les prohíba ${ }^{30}$. Habilitándose, por tanto, si se le añade una lectura amplia de la expresión de la nombrada STC 32/81

29 REQUEJO PAGÉS, J. L. El valor de la Carta Europea de la Autonomía Local en el ordenamiento español, en CAAMAÑO DOMÍNGUEZ, F. (coord.) La autonomía de los entes locales en positivo. Serie claves del gobierno local, 1, Fundación Democracia y Gobierno Local, Madrid-Barcelona, 2003. P. 30.

30 En esta línea encontramos a Francisco CAAMAÑO cuando afirma que, al definir el Tribunal Constitucional, en su Sentencia 193/1987 la Autonomía local como «la capacidad para decidir libremente entre varias opciones legalmente posibles, de acuerdo con un criterio de naturaleza esencialmente política», "se minusvalora la autonomía política, al considerarla como un poder discrecional dentro de la ley, cuando lo que caracteriza a la autonomía política es, precisamente, la capacidad de decidir -y, claro está, responder ante la ciudadanía-, incluso en ausencia de Ley». CAAMAÑO DOMÍNGUEZ, F. Autonomía local y principio de subsidiariedad. Informe de la Secretaría de Estado de Relaciones con las Cortes, $\mathbf{M}^{\circ}$ de la Presidencia, 2004. P. 11. 
«de cuantos asuntos le atañen», la posibilidad de la competencia universal de la Administración local ${ }^{31}$.

La Carta Europea de la Autonomía Local, en su articulado, no dispone de ningún mecanismo de garantía y tutela propio, no prevé órganos jurisdiccionales propios para determinar el sentido y alcance de sus preceptos, ni su régimen de aplicación frente a otras normas, de modo que esas funciones deberán llevarse a cabo por los órganos judiciales internos de cada Estado. Así, a diferencia de otros Tratados como el Convenio Europeo de Derechos Humanos, no se prevé ninguna «Corte Europea» que tenga la última palabra acerca del sentido de los preceptos de nuestra Carta. Por otra parte, y también a diferencia del Convenio Europeo, la Carta contiene principios, directrices, deseos, intenciones..., mientras que el Convenio recoge la regulación de derechos, su establecimiento, garantías, etc.

Por lo que se refiere al valor de la Carta, como el Tratado internacional que es, será el derivado de su consideración como parte del ordenamiento jurídico interno, una vez ratificado por el reino de España. En cuanto al lugar que la Carta ha de ocupar, como tal Tratado, hay que indicar que, en principio, no ocuparía una especial o singular posición en el ordenamiento que le permita condicionar la validez de normas con valor legal. Si bien hay autores, básicamente de la doctrina científica administrativista, que, como Luciano PAREJO, atribuyen a la Carta el valor y la fuerza normativa propia de las leyes asimilándola a la Ley Reguladora de las Bases de Régimen Local ${ }^{32}$ o, como Luis ORTEGA, que va aún más allá al atribuirle una mayor intensidad de efectos, incluso, que la misma Ley de Bases, por operar a su juicio el principio de lex posterior y, además, no poder modificarse por el legislador básico ${ }^{33}$. En todo caso, y a la vista de determinada jurisprudencia del Tribunal Supremo -tal y como nos muestra el magistrado BANDRÉS ${ }^{34}$ - sí encontraremos un reconocimiento del valor normativo de la Carta Europea de la Autonomía

31 SÁNCHEZ SÁEZ afirma que dicha posibilidad ya existe en países de nuestro entorno jurídico -esto en algún caso podría ser discutible- como Francia, Italia, Alemania o Estados Unidos. SÁNCHEZ SÁEZ, A. Descentralización y Subsidiariedad: hacia una nueva configuración del Estado. IAAP, Sevilla, 2005.

32 PAREJO ALFONSO, L., "La Carta Europea de la Autonomía Local en el ordenamiento jurídico español» en Estudios sobre la Carta Europea de la Autonomía Local, Conferencia sobre la Carta Europea de la Autonomía Local, Barcelona, 23-25 de enero de 1992. Ajuntament de Barcelona, 1994. Pp. 81 y ss.

33 ORTEGA ÁlVAREZ, L., "La Carta Europea de la Autonomía Local y el ordenamiento jurídico español». REALA, n. ${ }^{\circ}$ 259. Año 1993. Pp. 475-497.

34 BANDRÉS SÁNCHEZ-CRUZAT, J.M., La Carta Europea de la Autonomía Local en la jurisprudencia del Tribunal Supremo en Cuadernos de Derecho Local n. ${ }^{\circ} 20$, Fundación Democracia y Gobierno Local, Junio de 2009. P. 14 y ss. 
Local. Así, se pone de manifiesto en su Sentencia de 23 de septiembre de 2008 (RC 474/2006), en la que se anula un Acuerdo del Consejo de Ministros que denegó la autorización de una consulta popular al Ayuntamiento de Almuñécar en base a una interpretación o «lectura armonizadora» de los artículos 1, 18.1.f) y 71 de la LRBRL, con los artículos 3 y 4 de la Carta. En dicha sentencia, el Tribunal Supremo se sirvió de lo previsto en los señalados artículos del Tratado para precisar el concepto de "competencias propias municipales», precisando que cuando de tales competencias se trata «no necesariamente deben ser plenas y completas». O en la Sentencia de 26 de julio de 2006 (RC 1346/2004), de 26 de julio, en la que, nuevamente, los artículos 3 y 4 del Tratado jugaron un papel fundamental para determinar el alcance de determinadas competencias locales, llegándose a afirmar literalmente en la Sentencia que «Es de entender que la Carta Europea de la Autonomía Local de 15 de octubre de 1985, que debemos aplicar pues nos obliga como elemento que es de nuestro ordenamiento jurídico, constituye un importante instrumento de interpretación del principio de autonomía local que consagra la Constitución [...]. Una interpretación de este tipo no hace sino cumplir la finalidad que atribuye a la jurisprudencia de este Tribunal Supremo el título preliminar del Código Civil cuando en su artículo 1.6 dispone que completará el ordenamiento jurídico [...]».

\section{5) LAS COMPETENCIAS LOCALES. CLASIFICACIÓN}

Las competencias locales, tal y como prevé el artículo 7 LRBRL, se clasifican en competencias propias y competencias atribuidas por delegación, en función de si son competencias que se ejercen en los términos establecidos por la legislación vigente pero autónomamente $^{35}$, sin sujetarse a las instrucciones de otras administraciones que vayan más allá de la mera coordinación interadministrativa (esto es, que no supongan un menoscabo de la capacidad decisoria y, por tanto, sin afectar a la autonomía de la entidad correspondiente, al tratarse de materias donde prevalecería un interés local) ${ }^{36}$ o si, por

35 «de forma libre, autónoma precisamente» dice el Profesor SOSA WAGNER y "en régimen de autonomía y autorresponsabilidad» afirma ROÁS MARTÍN. SOSA WAGNER, F., Aproximación básica a las competencias locales, en PARADA VÁZQUEZ, R. Y FERNÁNDEZ RODRÍGUEZ, C. (dirs.) Las competencias locales. Barcelona, 2007, p. 24. y ROÁS MARTÍN, P. L., "Posibilidades de reacción local frente a la problemática medioambiental: limitaciones competenciales y su incidencia en la autonomía local» en Cuadernos de Derecho Local n. ${ }^{\circ}$ 16, Fundación Democracia y Gobierno Local, Febrero de 2008, p. 116

36 Estaríamos ante las competencias que, autores como Luis ORTEGA, entienden que equivaldrían al contenido objetivo de la autonomía local. ORTEGA ÁLVA- 
el contrario, son competencias que las Comunidades Autónomas o el Estado les han transmitido (afectando, por tanto, a asuntos de interés local, aunque éste no sea el predominante), quedando los entes locales sometidos a la dirección y control del delegante ${ }^{37}$.

Las competencias propias se ejercen en régimen de autonomía y bajo la propia responsabilidad, atendiendo a la debida coordinación con las demás administraciones públicas y, a su vez, se subdividen en las estrictamente propias y las competencias propias sometidas a instrucciones. Las primeras son aquellas que deben ejercer, tanto municipio como provincia, sobre una relación de materias recogidas en el artículo 26 de la LRBRL (estableciéndose en función del número de habitantes), en lo que al municipio se refiere, y en el artículo 31.2 para la provincia (aquellas competencias que tengan por finalidad garantizar los principios de solidaridad y equilibrio intermunicipales asegurando la prestación integral y adecuada, en la totalidad de su territorio, de los servicios de competencia municipal). Por otro lado, las competencias propias sometidas a instrucciones son aquellas que se caracterizan porque para su ejecución, al tratarse de competencias que afectan a intereses más allá de los estrictamente locales, concurrentes con los de otras Administraciones, requieren de la correspondiente coordinación (art. 10.2 LRBRL) y se trataría, en el caso de los municipios, de las enumeradas en el artículo 25.2 de la LRBRL (seguridad en lugares públicos, ordenación del tráfico y personas en vías urbanas, protección civil, prevención y extinción de incendios, urbanismo, abastos, salubridad pública, cementerios, suministro de agua y otros servicios urbanos, actividades e instalaciones deportivas y culturales, etc.).

REZ, L., Las competencias propias de las corporaciones locales en MUÑOZ MACHADO, S. (dir.) Tratado de Derecho Municipal, Civitas, Madrid, 2003. P. 185 y ss.

37 En este caso, podríamos coincidir con REQUEJO RODRÍGUEZ, cuando afirma que "por mucho que el ente local conserve un cierto margen de decisión y actúe bajo su responsabilidad, este instrumento no parece a priori el más idóneo para reflejar el núcleo esencial de la autonomía local.» Igual ocurriría con las llamadas actividades complementarias, aunque "Más dudoso en ocasiones pueden resultar otros supuestos, como el previsto en el artículo 62 de la LBRL, de participación de los entes locales en actuaciones o procedimientos relativos a actividades en las que una asignación diferenciada de facultades decisorias entre las distintas administraciones interesadas resulte muy difícil o inconveniente, dejando por ello la decisión final en manos bien de la Administración estatal bien de la autonómica.» Y citando a ORTEGA ÁLVAREZ afirma que, en el caso de las competencias delegadas las entidades locales, no se estaría tanto ante una manifestación del contenido objetivo de la Autonomía local, como ante una manifestación de los entes locales como elementos de la organización territorial del Estado. REQUEJO RODRÍGUEZ, P., "El nuevo diseño de las competencias locales», en Cuadernos de Derecho Local..., op. cit., p. 31 y ss. 
Por su parte, el artículo 27 regula las competencias delegadas o transferidas, y serán aquellas que según el artículo 7.3 de la Ley de Bases, se ejercen en los términos de la delegación y pueden prever técnicas de dirección y control de oportunidad, respetando siempre la potestad de autoorganización de servicios de la entidad local ${ }^{38}$. A su vez, pueden ser las delegadas como tales y las asignadas o encomendadas. Las Delegadas como tales son competencias transferidas a las corporaciones locales (junto con los medios necesarios...) para lograr una gestión más eficaz ${ }^{39}$ y pueden delegarse las que contemplen tanto acciones materiales (ejecución de obras y prestación de servicios) como funcionales (el mero ejercicio de funciones administrativas) ${ }^{40}$. Conviene, a su vez, distinguir las competencias delegadas de las transferidas, éstas últimas tienen por objeto la titularidad de una competencia que, en principio, corresponde al ente titular (Estado o, más comúnmente, Comunidades Autónomas), mientras que el objeto de la delegación sería el mero ejercicio de la competencia por el ente local; en el primer caso, la transferencia se efectúa mediante Ley, en el caso de la delegación bastaría un Decreto. Por su parte, las competencias asignadas (estaríamos ante una variedad de las delegadas) serán aquellas encomendadas a las entidades locales para la gestión ordinaria de servicios propios de las Comunidades Autónomas o del Estado y, en estos casos, ejercerán, municipios ${ }^{41}$ y provincias, de simples órganos administrativos por cuenta de los entes que se las asignen ${ }^{42}$.

38 En la actualidad, podemos encontrar numerosos ejemplos de las técnicas de control y dirección en las normas reglamentarias autonómicas que regulan las convocatorias de las subvenciones, a través de las cuáles se articula la ejecución (y normalmente insuficiente financiación) de este tipo de competencias.

39 Encontramos aquí un claro ejemplo de cómo la LRBRL efectúa una regulación en desarrollo de los principios constitucionales proclamados en el artículo 103.1, singularmente, del principio de eficacia, de descentralización y de coordinación, también, en otro sentido, del de jerarquía.

40 Tal y como establece el artículo 27 LRBRL, en este tipo de delegación hay una voluntariedad por parte del municipio y la dotación económica debe ser fruto del acuerdo entre los entes. Además se caracteriza porque su objeto son las competencias compartidas o concurrentes y se produce una transferencia real del ejercicio de competencias, lo que tiene como consecuencia que el ente delegado actuará bajo su propia responsabilidad.

41 Recientemente la incorporación a nuestro ordenamiento de la conocida Directiva de servicios (Directiva 2006/123/CE) está proporcionando interesantes ejemplos de este tipo de competencias a los municipios por parte de las Comunidades Autónomas, que se manifiestan como un más que sugerente objeto de estudio en lo relativo, precisamente, a los recursos y medios de que se acompañan (o, justamente, lo contrario).

42 Este tipo de competencias se delegan, o mejor debería decirse se imponen, con carácter obligatorio, deben ir acompañadas necesariamente de la dotación de 
Por último, habría que añadir, que sobre ambas clases de competencias delegadas cabe la posibilidad del control y dirección de los servicios delegados, la posibilidad de emanar instrucciones y recabar cuanta información se necesite, así como requerir para la subsanación de las deficiencias que el delegante observe sobre los servicios delegados. En caso de incumplimiento de directrices o requerimientos se podrá revocar la delegación.

En todo caso, sí es de reseñar que a pesar de lo previsto en el artículo 7 (la definición de los dos tipos de competencias, propias y atribuidas por delegación) la LRBRL no establece qué tipo de competencias ejercerá el municipio en el caso de las materias en las que ha de recibir necesariamente alguna competencia, correspondiendo por tanto esa decisión al legislador sectorial competente por razón de la materia.

En lo que se refiere al caso concreto de las delegaciones o asignaciones de competencias de las Comunidades Autónomas a las Diputaciones provinciales, el artículo 37 de la LRBRL establece que podrán delegarles competencias, así como encomendarles la gestión ordinaria de servicios propios, en los términos previstos en los Estatutos correspondientes, actuando las Diputaciones con sujeción plena a las instrucciones de las Comunidades. Esta fórmula se muestra de lo más oportuna e interesante en el actual escenario que tanto obliga a la racionalización, optimización y mayor eficiencia en las estructuras administrativas, en muchas ocasiones prácticamente duplicadas, especialmente en los casos de las administraciones periféricas de las Comunidades Autónomas pluriprovinciales donde los servicios administrativos de las distintas Diputaciones provinciales podrían prestarles el soporte necesario para la el cumplimiento de sus fines.

Por otra parte, y como se anticipó, del mismo modo que la LRBRL no establece una relación clara de materias sobre las que los entes locales hayan de ejercer el derecho a intervenir que tienen constitucionalmente garantizado, la regulación de las competencias locales tampoco puede fácilmente incluir, por corresponder al legislador sectorial, una determinación clara de las competencias que ostentan o puede atribuirse a municipios, provincias e islas sobre los

medios económicos apropiados, suponen una relación funcional jerárquica del delegante sobre el órgano correspondiente del «ente asignado», se efectúa con competencias plenas para la mera ejecución material y -tal y como afirma SOSA WAGNER- más que una trasferencia, lo que se produce es una simple utilización por el ente delegante de "órganos impropios». SOSA WAGNER, F., Aproximación básica a..., op. cit., p. 29. 
asuntos que afectan al círculo de sus intereses -en palabras de su artículo 2.1- que, entendemos, se deducen de lo previsto en los artículos 25, 26, 28, 31 y 36. De modo que nos encontramos con que, en la mayor parte de los casos, serán las Comunidades Autónomas las que determinarán el ámbito competencial de las Entidades Locales, sin dejar apenas margen para el ejercicio de la competencias normativas locales que, especialmente en lo referido a lo previsto en los artículos 25.2 y 26 , vienen a constituir buena parte del contenido objetivo de la Autonomía Local. En palabras de Paloma REQUEJO «Es claro, por tanto, que ni Constitución ni la Ley de bases establecen cuáles son las competencias locales y es imprescindible acudir para cerrar la cuestión a las leyes sectoriales a las que la propia Ley de bases remite» ${ }^{43}$, coincidimos con la profesora cuando señala lo general y vago de la formulación del mínimo competencial necesario para garantizar la autonomía local así como la limitación de la Ley de Bases para prever qué tipo de competencias deberán ejercerse sobre las materias del 25.2, por ejemplo ${ }^{44}$. Y, en lo que se refiere al artículo 25.1, podríamos afirmar que nos encontramos ante la perspectiva de un esquema competencial en el que a los entes locales se les concedería la facultad de asumir las tareas que les afecten, siempre y cuando no las desempeñe otra administración ${ }^{45}$. Como se ha señalado más arriba, junto a las competencias normativas, que en el caso local se manifiestan en la aprobación de las correspondientes Ordenanzas, Reglamentos y Bandos, encontramos las competencias ejecutivas, en las que se debe atribuir, además, una cierta capacidad de decisión sobre los asuntos en los que prevalece dicho interés local. Y, desde esta perspectiva, hay que señalar que la LRBRL, tal y como señala

43 REQUEJO RODRÍGUEZ, P., "El nuevo diseño de las competencias locales», en Cuadernos de Derecho Local... Op. cit., p. 30.

${ }_{44}$ Sobre dichas materias, apunta la profesora REQUEJO, autores como Eliseo AJA FERNÁNDEZ, Tomás FONT i LLOVET o Santiago MUÑOZ MACHADO señalan que la asignación de competencias deberá llevarse a cabo por el legislador sectorial. Coincidiríamos con Luis ORTEGA cuando propone que las materias del 25.2 requieren de competencias propias por entenderse así de modo mucho más apropiado la idea de autonomía local. ORTEGA ÁLVAREZ, L., Las competencias propias de los entes locales, en MUÑOZ MACHADO, S. (Dir.), Tratado de... Op. cit., p. 185 y ss.

45 En esta misma línea nos encontramos en perfecto acuerdo con ROÁs MARTÍN cuando afirma que «...la autonomía local no está constituida por un catálogo de competencias objetivamente determinado o que pueda determinarse sobre la base de unas características invariables, sino más bien mediante la facultad de asumir, sin título competencial especial, todas aquellas tareas que afecten a la comunidad vecinal que integra el municipio y que no hayan puesto en funcionamiento otras administraciones públicas.» ROÁS MARTÍN, P. L., "Posibilidades de reacción local frente a la problemática medioambiental: limitaciones competenciales y su incidencia en la autonomía local» en Cuadernos de Derecho Local n. ${ }^{\circ}$ 16, Fundación Democracia y Gobierno Local, Febrero de 2008. p. 116. 
LÓPEZ GARCÍA ${ }^{46}$ "establece una mera presencia testimonial de las entidades locales en la gestión de los grandes servicios públicos-sanidad, seguridad social y educación-que constituyen la esencia del Estado social y democrático que proclama la constitución», de tal manera que si, como ya se ha indicado, solamente cabe hablar de Autonomía en el caso de ejercicio de competencias propias, la realidad nos muestra un panorama en el que no se ha consumado el esquema planteado por la LRBRL, dado que las leyes sectoriales, en la mayor parte de las ocasiones, ni siquiera atribuyen competencias a los gobiernos locales haciéndolo, en su caso, muy limitadamente mediante la delegación de funciones sometidas a estrecheces financieras e instrucciones de funcionamiento propias de un esquema con una distribución territorial del poder en la que los Entes Locales juegan un papel, en gran medida, restringido y coartado. A este respecto conviene recordar las reflexiones de SANTAMARÍA PASTOR y CAAMAÑO DOMÍNGUEZ ${ }^{47}$ en las que se ponían de manifiesto las deficiencias de un esquema en el que se define negando o señalando lo que no debe ser, de modo que en vez de establecer una lista definida de competencias locales lo que se hace es poco más que imponer al legislador estatal y autonómico el límite de no desfigurar hasta hacer irreconocible la institución local en cuestión.

\section{6) LAS COMPETENCIAS LOCALES EN EL PROYECTO DE LEY DE RACIONALIZACIÓN Y SOSTENIBILIDAD DE LA ADMINISTRACIÓN LOCAL}

El 6 de septiembre de 2013 vio la luz en el Boletín Oficial de las Cortes Generales el acuerdo de la Mesa del Congreso de los Diputados por el que se publicó 1 Proyecto de Ley de racionalización y sostenibilidad de la Administración Local, abriéndose entonces el plazo de enmiendas. No pretende ser este un análisis exhaustivo del mencionado documento visto, además, lo temprano del estado de tramitación de la modificación legal pretendida, no obstante resulta inevitable efectuar al menos determinadas consideraciones ante lo que se nos presenta como una nueva intervención legislativa sobre

46 LÓPEZ GARCÍA, C., Nuevo sistema de atribución y defensa competencial de las entidades locales, en Cuadernos de Derecho Local n. ${ }^{\circ} 15$, Fundación Democracia y Gobierno Local, Octubre de 2007, p. 112.

47 SANTAMARÍA PASTOR, J. A. "Notas sobre la sentencia de las Diputaciones provinciales» en Revista Española de Derecho Constitucional, Año n. ${ }^{\circ}$ 2, n. ${ }^{\circ}$ 6, septiembre-diciembre 1982, pp. 179-208. CAAMAÑO DOMÍNGUEZ, F. «Autonomía local y Constitución» en Revista Española de Derecho Constitucional, Año n. ${ }^{\circ} 24$, n. ${ }^{\circ} 70$, enero-abril 2004. pp. 161-188. 
el régimen local que, desde luego en lo referido a las competencias locales, parece nacer con vocación de acabar resultando un nuevo fracaso.

El mencionado Proyecto de Ley de racionalización y sostenibilidad de la Administración Local, en su exposición de motivos y tras poner de manifiesto la finalidad a la que aspira -veremos que de modo absolutamente frustrante- y que no es otra que «someter a una revisión profunda el conjunto de disposiciones relativas al completo estatuto jurídico de la Administración Local», llama la atención sobre la evidencia de las disfuncionalidades generadas por el modelo competencial diseñado por la Ley Reguladora de las Bases del Régimen Local. Y señala la clarificación de las competencias locales para evitar duplicidades con las de otras Administraciones como uno de los objetivos básicos que dice perseguir, llega incluso a proclamar que hará efectivo el principio «una Administración una competencia».

Centrándonos, en las modificaciones pretendidas para las previsiones del Capítulo Tercero del Título II de la vigente Ley reguladora de las Bases del Régimen Local que, como se ha señalado se integra por los artículos 25 al 28 en el caso de los municipios, llama la atención primeramente la supresión del último de ellos, si bien como veremos más adelante sin que ello suponga gran avance sobre la materia. Señalaba la exposición de motivos antes aludida que «...se enumera un listado de materias en que los municipios han de ejercer, en todo caso, competencias propias...» refiriéndose básicamente la nueva redacción prevista para el artículo 25. No obstante, habría que comenzar señalando que, ya desde el punto 1, apreciamos una adición significativa a la conocida como cláusula de competencia general por limitarse con la expresión «...en los términos previstos en este artículo». En lo que respecta al 25.2, tras la mención al carácter propio de las competencias que ejerce el municipio sobre determinadas materias, sorprende al lector una relación muy, muy similar a la vigente en la que además se observan carencias técnicas relevantes por mezclarse indistintamente competencias con materias, así como omisiones clamorosas en la era de las telecomunicaciones. De modo explícito, en el punto tercero, reitera la exigencia de Ley para determinar las competencias municipales y evaluar la conveniencia de la implantación de los servicios locales correspondientes y, como sucede insistentemente en el resto del Proyecto de Ley, se señala en el punto cuarto la necesidad de que la Ley que determine las competencias municipales sobre las materias enunciadas, al prever la dotación de recursos necesarios para asegurar la suficiencia financiera, 
lo hará «sin que ello pueda conllevar, en ningún caso, un mayor gasto de las Administraciones Públicas».

En el artículo 26, donde se relacionan una serie de servicios que con carácter obligatorio han de prestar los municipios, se comienza por suprimir la expresión "por sí o asociados» que recogía la vigente Ley de Bases, así como alguna de las funciones anteriores tales como el control de alimentos y bebidas. Y es en el 26.2 donde encontramos la temida por incierta, escasamente respetuosa con el principio democrático que funda la Autonomía municipal, y de dudosa constitucionalidad, coordinación de las Diputaciones provinciales (o entidades equivalentes) para la prestación de los servicios de recogida de residuos, limpieza viaria, abastecimiento domiciliario de agua potable, acceso a núcleos de población, pavimentación de vías y tratamiento de residuos. Servicios estos sobre lo que caía la sospecha de una posible privatización, como finalidad encubierta del Proyecto de Ley, tal y como han denunciado determinadas posiciones políticas al entender que esta reforma habilitaría y facilitaría los cauces legales para llevarla a efecto, el texto redactado por el Gobierno parece darles la razón.

El artículo 27 regula la delegación de competencias por el Estado y las Comunidades Autónomas en los municipios introduciendo como principal novedad el plazo mínimo de delegación que se establece en cinco años insistiendo en el consabido "...sin que pueda suponer un mayor gasto de las Administraciones Públicas» recogiendo, asimismo, la necesidad de unos "criterios homogéneos» que no se precisan para efectuar la delegación y previendo la posibilidad de solicitar la asistencia de, otra vez, las Diputaciones provinciales (o entidades equivalentes) para la coordinación y seguimiento de las delegaciones competenciales comunes (del Estado y las Comunidades Autónomas). Enumera en el 27.3 las competencias delegables, nuevamente dice "siguiendo criterios homogéneos», que se corresponden básicamente con las que vienen ejerciendo los municipios al amparo de lo previsto en el vigente artículo 28, ahora suprimido. Finalmente, en el punto sexto, recoge la nulidad de cuantas delegaciones no se acompañen de la correspondiente dotación presupuestaria adecuada y suficiente, y establece -que nos parece nada carente de interés- la habilitación a la entidad local delegada para, en caso de incumplimiento de las obligaciones financieras por la Administración, eso sí autonómica, delegante compensar de modo automático con otras obligaciones financieras que aquella tenga con esta última. 
En lo relativo a las competencias de las Diputaciones provinciales, escasas son las aportaciones de las modificaciones al artículo 36, excepción hecha de lo ya mencionado en relación a la coordinación de «...la prestación unificada de servicios de los municipios de su respectivo ámbito territorial». No obstante, pretende el nuevo texto adecuar a los tiempos actuales algunas de las competencias que ejercen las Diputaciones recogiendo expresamente entre las propias la prestación de los servicios de Administración electrónica y la contratación centralizada en los municipios con población inferior a 20.000 habitantes, así como expresamente la asistencia en la prestación de los servicios de gestión de la recaudación tributaria, o el apoyo a la gestión financiera en municipios, también, de menos de 20.000 habitantes, labores estas últimas que sí vienen desarrollando a día de hoy. Y, por supuesto, en la línea que preside todo el Proyecto de Ley, recoge expresamente "El seguimiento de los costes efectivos de los servicios prestados por los municipios de su provincia». Por último, en el punto segundo de este artículo 36 insiste en el coste efectivo de los servicios señalando que "Cuando la Diputación detecte que los costes efectivos de los servicios prestados por los municipios son superiores a los de los servicios coordinados o prestados por ella, incluirá en el plan provincial fórmulas de prestación unificada o supramunicipal para reducir sus costes efectivos. El Estado y la Comunidad Autónoma, en su caso, pueden sujetar sus subvenciones a determinados criterios y condiciones en su utilización o empleo y tendrán en cuenta el análisis de los costes efectivos de los servicios de los municipios» y recoge expresamente el apoyo a los municipios en el desempeño de funciones públicas necesarias para selección y formación de personal así como dando soporte a los Ayuntamientos en la tramitación de procedimientos administrativos, asumiendo incluso las actividades materiales y de gestión que se les encomienden.

\section{7) A MODO DE CONCLUSIÓN}

Como conclusión, junto a la tantas veces apuntada necesidad de que el legislador establezca un «catálogo» de competencias locales ${ }^{48}$ (reclamación que se ha efectuado de modo reiterado por los entes

48 Respondiendo así, de modo claro, eficaz y satisfactorio, a la exigencia del propio Tribunal Constitucional cuando ya en su Sentencia 4/1981, de 2 de febrero, afirmaba que "De aquí que el art. 137 CE delimite el ámbito de estos poderes autónomos, circunscribiéndolos a la 'gestión de los respectivos intereses', lo que exige que se dote a cada Ente de todas las competencias propias y exclusivas que sean necesarias para satisfacer el interés respectivo». 
locales, en orden básicamente a clarificar su financiación), debe señalarse lo acertado de la expresión de Francisco SOSA WAGNER cuando afirma que Autonomía y competencias son nociones perfectamente unidas ${ }^{49}$. En todo caso, dicho catálogo habría de incluir un listado de materias sobre las que se establezca la competencia local en concreto, lo que implicaría, necesariamente, modificar el modelo actual basado en los intereses locales, así como el esquema vigente de atribución de competencias por los legisladores sectoriales, sustituyéndose éstos por el legislador básico estatal junto con el legislador estatutario, propiciando la creación del llamado «bloque de la constitucionalidad local $\aleph^{50}$ y reforzando, por tanto, la posición objetiva -por seguir el esquema de FANLO LORAS- de los entes locales respecto del legislador sectorial. En su lugar, si no se procede en la línea que se sugiere, seguiremos encontrándonos una realidad de los hechos en la que la práctica continuada del legislador sectorial (singularmente autonómico) ha omitido, o descartado, reiterada y sistemáticamente la atribución de competencias a los entes locales, inclinándose permanentemente por la delegación de competencias mediante un perverso régimen subvencional, lo que a su vez nos pone de manifiesto que, si Autonomía y competencias están íntimamente unidas, un ámbito competencial tan limitado, restringido, insuficientemente financiado y sometido continuamente a instrucciones nos revela el estado en que se nos presenta nuestra Autonomía local, por muy constitucionalmente garantizada que se encuentre.

Nuestro modelo de 1985 establece que el legislador básico estatal ha de establecer principios básicos y directrices en relación a la asignación de competencias que, más tarde, el legislador sectorial habrá de llevar a cabo. Actualmente podemos afirmar, sin dejar lugar al error, que lo que existe es el deber de asegurar el derecho a intervenir, pero poco más; expresiones no exentas de vaguedad como las que encontramos en los mencionados artículos 25 y 26 -tanto de la Ley de Bases en vigor como de la modificación proyectada- no contribuyen a una adecuada, concreta y, sobre todo, operativa y práctica definición del esquema competencial; la exigencia del Tribunal Constitucional, contenida en su Sentencia 4/81, de 2 de febrero, de que se

49 Podría añadirse, además, suficiencia de recursos, y lo cierto, a día de hoy, es que cuando hablamos de Autonomía, competencias y financiación locales se abre ante nosotros un enorme camino por recorrer en el que se han dado poco más que los primeros y, no obstante, vacilantes pasos.

50 En la línea doctrinal ya apuntada por GARCÍA ROCA, J. en El concepto actual de autonomía local... en LÓPEZ GUERRA, L. (Coord.) Estudios de Derecho Constitucional. Homenaje al Profesor Dr. D. Joaquín García Morillo. Tirant Lo Blanch, Valencia, 2001. Pp. 655 y ss. 
dote a cada Ente de todas las competencias propias y exclusivas que sean necesarias para satisfacer el interés respectivo, sigue sin atenderse por el legislador competente ${ }^{51}$. $\mathrm{Y}$, la realidad es que ni el legislador básico estatal ha podido determinar con claridad esos principios, criterios y directrices, ni el legislador sectorial (sobre todo el autonómico) ha asignado competencias más allá de la mínima participación mediante los controles y limitaciones propios del régimen subvencional. De ahí, además, la importancia de que se proceda a la modificación del esquema actual, vigente desde la Ley 7/1985, de 2 de abril, de Bases del Régimen Local, y se acepte la inconveniencia de que sea el legislador sectorial quien atribuya las competencias, para así encuadrar dichas funciones en el «bloque de la constitucionalidad», haciendo corresponder, por tanto, a la legislación básica estatal así como a los Estatutos de Autonomía ${ }^{52}$ el papel de normas atributivas de competencias lo más precisas y expresas posibles ${ }^{53}$ - pretensión $^{2}$

51 Lo cierto, a día de hoy, es que la práctica totalidad de las materias sobre las que las entidades locales han venido reclamando competencias (consumo, deportes, educación, empleo, juventud, mujer, medio ambiente, ordenación del territorio y urbanismo, patrimonio histórico-artístico, protección civil, sanidad, servicios sociales, transportes, turismo, etc.) corresponden en la actualidad a las Comunidades Autónomas y compete, por tanto, a las mismas el efectuar transferencias competenciales, preferiblemente, a las entidades locales -quizás como se ha sugerido- en el marco de unos «pactos locales autonómicos» que deberían producirse cuanto antes. GARCÍA RUBIO, F., La segunda descentralización. Bases para pactos locales en las Comunidades Autónomas, Centro de Estudios Políticos y Constitucionales, Madrid, 2003, p. 33.

52 Para un estudio de las reformas de las regulaciones estatutarias en materia de régimen local y, singularmente, acerca de las competencias locales vid. REQUEJO RODRÍGUEZ, P., "El nuevo diseño de las competencias locales», en Cuadernos de Derecho Local..., op. cit., pp. 34 y ss.

53 En esta línea, aunque con las limitaciones que veremos, parecería haberse encaminado el legislador al menos tras el reciente proceso de reformas estatutarias. Si bien, aunque algunos de los que podríamos considerar más avanzados Estatutos de Autonomía han recogido en su articulado relaciones de materias en las que se atribuyen a los municipios competencias propias, por otro lado, es una constante el recurso a la necesidad de que sea el legislador autonómico quien precise la concreta "distribución de responsabilidades administrativas entre administraciones» así como su financiación. En palabras de la profesora REQUEJO «Con sus más y con sus menos vemos que la tónica de las reformas es [...] clarificar el alcance de las competencias autonómicas que se asumen en materia local [...] dar en muchos casos un paso adelante respecto de la participación de los entes locales en las materias que les afecten» pero, por otro lado, «la regulación estatutaria, sin restringir el ámbito que constitucionalmente les corresponde a los entes locales, es una forma de potenciar la autonomía de la comunidad pues [...] no dejan de tener un carácter bifronte en tanto elementos esenciales tanto de la organización estatal como autonómica». REQUEJO RODRÍGUEZ, P., «El nuevo diseño de las competencias locales», en Cuadernos de Derecho Local..., op. cit., p. 38. Por otra parte, CASIMIRO LÓPEZ nos señalará que «Si la doctrina esperaba grandes novedades de los nuevos estatutos en la consolidación de un concepto amplio de autonomía constitucional de los entes locales, con una relación de servicios y competencias propias, incluidas fundamentalmente las legislativas, ya puede decirse 
ésta a la que no podría responder en absoluto el Proyecto de Ley de racionalización y sostenibilidad de la Administración Local. De modo tal que, como afirma GARCÍA ROCA, la función constitucional que la LBRL debe cumplir, garantizar unas competencias locales de la manera más concreta posible, permite quizá abandonar la imprecisa 'garantía institucional'. La Constitución impone al legislador estatal la labor de atribuir a Municipios y Provincias de forma general y permanente, como corresponde a una disposición que integra el bloque de la constitucionalidad, un ámbito competencial, no necesariamente de mínimos sino lo más preciso posible y ligado al interés local. ${ }^{54}$. Para ello, es imprescindible superar el planteamiento sentado por el Tribunal Constitucional en su Sentencia 240/2006, de 20 de julio, donde va a negar de modo categórico -y ciertamente controvertido- a la LRBRL su posición, como integrante del «bloque de la constitucionalidad», ya que el Tribunal afirmó que si se había recurrido a esa idea fue para comprobar si una concreta disposición vulneraba el orden constitucional de competencias en materia de régimen local ${ }^{55}$, entendido como régimen jurídico de las administraciones locales, lo que no equivale a Autonomía local ${ }^{56}$. Además, La LRBRL es una ley

que tales expectativas no se han cumplido [...] Se constata así el denunciado fracaso de una política que parece agotarse en el vicio de la reforma por la reforma que se denuncia por García de Enterría con cita de Burke». LÓPEZ GARCÍA, C., Nuevo sistema de atribución y defensa competencial de las entidades locales, en Cuadernos de Derecho Local... op. cit., p. 122.

54 Coincidimos, por tanto, con Javier GARCÍA ROCA cuando afirma que: «Considero, pues, conveniente fijar con rigidez mayor a la de ley ordinaria y dentro del bloque de la constitucionalidad un núcleo competencial -intocable por el legislador sectorialde funciones propias de las entidades locales en distintas materias». En cuanto al recurso, una vez más, al interés local entendemos que consideraciones como las recogidas en este trabajo acerca de la conveniencia de la superación del modelo basado en la contraposición interés local-interés general podrían aportar solución a los obstáculos que plantea la identificación de los intereses estricta y/o exclusivamente locales. GARCÎA ROCA, J. El concepto actual de autonomía local... en LÓPEZ GUERRA, L. Estudios de Derecho Constitucional. Homenaje al Profesor..., op. cit., p. 663-664.

55 Así, la mencionada STC 240/2006 tendrá como resultado la clarificación, al menos, de la posición de la LRBRL. En palabras de VELASCO CABALLERO, "Aun dando apariencia de continuidad con la jurisprudencia anterior, el Tribunal Constitucional declara con rotundidad que las normas de la LBRL no son canon constitucional de autonomía local. Pueden ser, sin duda, canon de constitucionalidad competencial (frente a leyes autonómicas), pero esto es algo notoriamente distinto. Se pone fin así a una imprecisa reclamación de 'posición' o 'función' constitucional especial para la $L B R L$, función ésta a la que hace referencia el propio Preámbulo de la LBRL y que llega hasta hoy» VELASCO CABALLERO, F., "Autonomía municipal» Ponencia en el II Congreso de la Asociación Española de Profesores de Derecho Administrativo, Santander, 2 de febrero de 2007. P. 37.

56 A este respecto, el profesor GARCÍA ROCA se mostrará tremendamente crítico con esta sentencia, en este y otros extremos, afirmando que "El argumento de que se trata de una jurisprudencia emanada en procesos de inconstitucionalidad y que por 
estatal de carácter básico, pero eso no le da una posición constitucional distinta a de la de las leyes ordinarias estatales que podrían modificarla, sin necesariamente devenir inconstitucionales. Así, la Sentencia afirmará que la LRBRL no se integra en el «bloque de la constitucionalidad» ni constituye canon de validez respecto de otras leyes estatales ${ }^{57}$.

Por otra parte, y como forzoso complemento a lo anterior, en relación a la situación actual de las competencias locales se haría indispensable que, como también señala Mayte SALVADOR, se habilite la, cada día más necesaria, presencia de las Corporaciones locales en el proceso legislativo, como ya está ocurriendo en algún supuesto del Derecho Comparado ${ }^{58}$. Por su parte, GOIG MARTÍNEZ y NÚÑEZ MARTÍNEZ, en la misma línea proponen que se lleve a cabo la articulación de la presencia y participación, tanto orgánica como funcional, de los entes locales en los niveles estatal y autonómico, a través del Senado en las Comisiones sectoriales y en los Consejos y Comisiones de coordinación, en el primer caso, y mediante las asambleas legislativas de las Comunidades Autónomas y en las equivalentes Comisiones y Consejos a nivel regional ${ }^{59}$. Con

ello no puede ser trasladado a este proceso conflictual, carece de consistencia doctrinal y es incoherente con la misma jurisprudencia constitucional, porque los recursos que resuelven controversias competenciales entre el Estado y las comunidades autónomas son verdaderos 'conflictos de competencia legislativa' entre entes territoriales en su naturaleza y tratamiento procesales antes que control normativo abstracto y directo.» GARCÍA ROCA, J., "La primera sentencia constitucional sobre el conflicto en defensa de la autonomía local (STC 240/2006): una ocasión perdida» en Cuadernos de Derecho Local, n. ${ }^{\circ}$ 14, Fundación Democracia y Gobierno Local, junio, 2007. P. 22.

57 Sobre este extremo, nuevamente, GARCÍA ROCA se preguntará "¿Qué sentido tiene una LBRL que debe por definición rellenar de contenido la autonomía local, concretizar la Constitución y los estatutos de autonomía, si esa función que es prolongación de la Constitución por su misma naturaleza no tiene unas mínimas dosis de estabilidad y resistencia pasiva? ¿Quién va a conformar y liderar el nuevo régimen local?». Por otra parte, añadirá una nueva crítica en relación al rechazo de la consideración de los Estatutos de autonomía como canon de enjuiciamiento del conflicto en defensa de la autonomía local, por contener éstos detalladas regulaciones de la autonomía local. Op. cit., p. 22.

58 Francisco SOSA WAGNER nos apunta el caso del Derecho alemán, donde el Reglamento del Bundestag ha previsto el trámite de audiencia a las entidades locales en el proceso legislativo cuando se trate de proyectos que les afecten. En nuestro caso dicha participación se ha resuelto, en nuestra opinión insatisfactoriamente, con las distintas regulaciones de la intervención de las entidades locales, a través de su asociación correspondiente, en la fase de redacción de borradores de proyectos tanto de normativa autonómica como estatal. SOSA WAGNER, F., Aproximación básica a... Op. cit., p. 21.

59 GOIG MARTÍNEZ, J. M. y NÚÑ̃Z MARTÍNEZ, M. A., "¿Reformar antes que culminar? Una nueva descentralización territorial fracasada. La autonomía local.» En La reforma de los Estatutos de Autonomía. Actas del IV congreso nacional de la 
el esquema competencial actual, los entes locales solamente podrán garantizarse en positivo la configuración de un contenido objetivo de la Autonomía Local, acorde con su relevancia en nuestro sistema constitucional de convivencia, a través de una participación activa, trascendental y significativa en el ejercicio de la potestad legislativa de Estado y Comunidades autónomas. Participación que en nada se ha materializado en la redacción del Proyecto de Ley de racionalización y sostenibilidad de la Administración Local que nace ya como un nuevo ejercicio de frustración para el mundo local, alejadísimo de la grandilocuencia de la finalidad que señalaba en su exposición de motivos al proclamar que «transcurridos casi treinta años desde la entrada en vigor de la Ley 7/1985, de 2 de abril, reguladora de las Bases del Régimen Local, y con más de una veintena de modificaciones de su texto original, cabe señalar que ha llegado el momento de someter a una revisión profunda el conjunto de disposiciones relativas al completo estatuto jurídico de la Administración local. Con este propósito se plantea esta reforma que persigue varios objetivos básicos: clarificar las competencias municipales... racionalizar la estructura organizativa de la Administración local... garantizar un control financiero y presupuestario más riguroso... y favorecer la iniciativa económica privada...». A día de hoy, recién publicado el Proyecto, claramente puede afirmarse que, a la vista del texto proyectado, solamente se abren las posibilidades correspondientes al cumplimiento del último de los objetivos: favorecer la iniciativa económica privada, lo que no es negativo en sí, pero resulta absolutamente frustrante y, obviamente, insuficiente.

Cabe concluir, asimismo, que las competencias locales han venido a ser el campo de batalla donde se produce la pugna entre el Estado, erigido en garante de la Autonomía de los entes locales (definida como el derecho a intervenir en cuantos asuntos afecten al círculo de sus intereses), y las Comunidades Autónomas, que ven como una amenaza a su ámbito competencial, tanto el papel de garante de la Autonomía que se atribuye el Estado, como la posibilidad de unos entes locales con competencias propias, claras y suficientemente financiadas. Y esta situación sitúa a nuestros entes locales en una posición que, sin lugar a dudas, se encuentra muy alejada de la que les correspondería como elementos principales y fundamentales de la organización territorial del Estado, que les reserva nuestra Constitución.

Asociación de constitucionalistas de España, RUIZ-RICO RUIZ, Gerardo (coord.). Universidad de Jaén-Tirant lo Blanc, Valencia, 2006. 